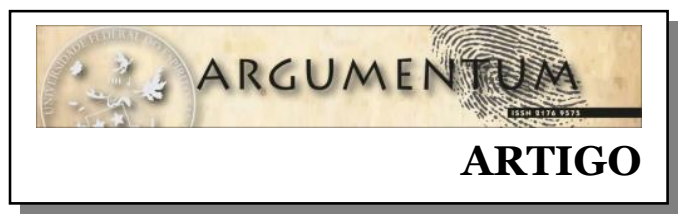

\title{
Trabalho social com famílias nos serviços de acolhimento institucional infanto-juvenil
}

\author{
Social work with families within institutional child and youth care services

\section{Izabel Herika Gomes Matias CRONEMBERGER* Solange Maria TEIXEIRA**}

\begin{abstract}
Resumo: O artigo, fundamentado em pesquisa (2014-2017) ao longo do Doutoramento em Políticas Públicas, apresenta discussão acerca do Trabalho Social com Famílias (TSF), planejado e executado por assistentes sociais nos serviços de acolhimento institucional para crianças e adolescentes. Recorre à pesquisa bibliográfica e documental aliadas à pesquisa de campo com profissionais de Serviço Social nesse espaço sócio ocupacional. O paper traz parte dos resultados obtidos à luz da análise do material empírico das entrevistas exploradas via método dialético crítico. Infere-se que o TSF, na maioria das vezes, é imediatista e sem encadeamento de ações que assegurem suporte à emancipação das famílias e à reintegração familiar. Essa, por sua complexidade, acaba relegada diante das dificuldades enfrentadas, obstruindo-se o verdadeiro sentido do Direito à Convivência Familiar e Comunitária.
\end{abstract}

Palavras-chave: Família. Acolhimento institucional. Trabalho social com famílias. Assistente Social. Política de Assistência Social.

\begin{abstract}
The article, based on research (2014-2017) carried out during a PhD in Public Policies, presents a discussion about family social work, planned and executed by social workers in institutional care services for children and adolescents. It calls upon bibliographic and documentary research associated to the field of professionals of Social Service in this social and occupational space. The paper also shows some of the results obtained from interviews analyzed by the critical dialectic method. Overall, the research infers that family social work is frequently short-termist. Therefore, it does not lead to the emancipation of families and to family reintegration. Due to its complexity and the difficulties they face, the families end up being relegated to a secondary role and the true meaning of the right to family and community living is obstructed.

Keywords: Family. Institutional care services. Social work with families. Social worker. Social Welfare Policy.
\end{abstract}

\section{Introdução}

Mioto (2010) evidencia que a família é um sujeito privilegiado de intervenção do Serviço Social desde os primórdios. Na origem as orientações dessa intervenção mantêm seu fundamento na doutrina social católica. Posteriormente, com a adesão ao positivismo, registra-se forte fundamentação em sua corrente funcionalista, resultando num trabalho conservador, estabelecido mais em elementos morais do que em condições verdadeiramente objetivas e subjetivas das famílias, mantendo conotação psicologizante e individualizante.

\footnotetext{
* Assistente Social. Doutora em Políticas Públicas (UFPI). Docente do Centro Universitário Santo Agostinho (UNIFSA, Teresina (PI), Brasil). Avenida Valter Alencar, $\mathrm{n}^{\circ}$ 665, São Pedro, Teresina (PI). CEP: 64.019-625. E-mail: <izabel_herika@hotmail.com>. ORC ID: < http://orcid.org/oooo-ooo2-9412-1879>.

${ }^{* *}$ Pós-Doutora em Serviço Social. Docente do Departamento de Serviço Social e do Programa de Mestrado e Doutorado em Políticas Pública da Universidade Federal do Piauí (UFPI). Campus Universitário Ministro Petrônio Portela, Bairro Ininga, Teresina (PI). CEP: 64049-550. E-mail: <solangemteixeira@hotmail.com>. ORC ID: < http://orcid.org/oooo-0002-8570-5311>.
} 
Na América Latina, anos 6o, registra-se intenso movimento de reconceituação da profissão de assistente social, o qual, no Brasil, alcança maior densidade um pouco depois, década de 8o, quando os profissionais passam a discutir sua ocupação sob a ótica da teoria social marxista. Essa fundamentação permite tanto o avanço teórico-metodológico da profissão quanto à construção de Projeto Ético-Político (PEP). Em relação à discussão sobre família e Trabalho Social com Famílias (TSF) relega-se o tema como objeto de estudo, visto como conservador, embora prossiga a ser demandado como elemento de intervenção da profissão.

Na contemporaneidade, desde os anos 90, a família ressurge como importante agente na proteção social, resgatada como parceira dos serviços públicos e privados. É um momento de ênfase nas reformas neoliberais e na ideia de que a proteção social é responsabilidade de todos. Não apenas financiando, mas principalmente executando, com seus recursos humanos, materiais e até financeiros ou com pequenos financiamentos pelo Estado. A família assume centralidade em muitas políticas públicas e o direito à convivência familiar e comunitária passa a ser lido como de reponsabilidade da família na sua garantia.

Ademais, a centralidade da família nas políticas sociais reatualiza as demandas pelo TSF para as equipes interdisciplinares, sendo o Serviço Social reconhecido como a área detentora desse saber teórico e técnico-operativo especializado. Renasce a produção científica sobre o tema e maior interesse em fundamentar teoricamente as intervenções. Regidos por um novo referencial teórico-metodológico crítico e pelo Projeto Ético-Político (PEP), a produção e o trabalho profissional afastam-se do teor conservador em busca de compreender e trabalhar a realidade circundante sob perspectiva acentuadamente crítica.

Porém, as políticas sociais são per se contraditórias. No caso em discussão, requisitam o TSF em meio a dubiedades que reeditam visões e práticas tradicionais, ao mesmo tempo em que podem ser espaços de trabalhos alternativos e com base nos interesses das famílias. Assim, o artigo objetiva analisar o Trabalho Social com Famílias, planejado e executado por assistentes sociais nos serviços de acolhimento institucional para crianças e adolescentes. Fundamentase em pesquisa ampla, realizada entre 2014 e 2017, ao longo do Doutoramento em Políticas Públicas, intitulada $\mathrm{O}$ processo de trabalho da/o assistente social nos serviços de acolhimento institucional no Estado do Piauí (CRONEMBERGER, 2017).

Considerando a inexistência de categorização consensual no que se refere à tipologia das investigações científicas, com a ressalva de que, cada vez mais, elas demandam conjunção de métodos e técnicas, a pesquisa em pauta configura-se como qualitativa, descritiva e bibliográfica. A qualitativa privilegia particularidades e experiências individuais, haja vista que seu alvo é apreender o comportamento de determinado grupo social, o que não impede, às vezes, a junção das duas modalidades, quando da chamada pesquisa quali-quantitativa. A pesquisa descritiva, como a própria designação sugere, limita-se a abordar quatro aspectos - descrição, registro, análise e interpretação de fatos ou fenômenos de determinada realidade, sem manipulá-los. A pesquisa bibliográfica, por sua vez, permite ao investigador cobertura mais ampla, uma vez que propicia reflexão sobre diferentes aspectos alusivos ao problema de pesquisa, mediante acesso a fontes bibliográficas e/ou eletrônicas, o que favorece novos enfoques e conclusões inovadoras (MARCONI; LAKATOS, 2011). 
Indo além, trata-se de pesquisa de campo, que corresponde à análise do objeto de estudo em seu próprio cenário e ambiente de vivência. No caso, diz respeito ao momento em que os pesquisadores utilizam a técnica de entrevista semiestruturada (roteiro não rigidamente delineado, o que o torna flexível e adaptável à realidade) junto a 10 assistentes sociais de diferentes instituições de acolhimento e da $\mathbf{1}^{\underline{a}}$ Vara da Infância e Juventude (VIJ) de Teresina (PI), cujos resultados são discutidos e interpretados via método dialético crítico. Para tanto, seguem as diretrizes das Resoluções do Conselho Nacional de Saúde n. 196, de 10 de outubro de 1996; n. 251, de 7 de agosto de 1997; e do Comitê de Ética n. 466, de 12 de dezembro de 2012, para o consequente parecer consubstanciado do Comitê de Ética e Pesquisa da Universidade Federal do Piauí, aprovado no Parecer n. 1.971.786, que pontua a assinatura do Termo de Consentimento Livre e Esclarecido por parte dos entrevistados.

\section{Aspectos históricos da profissão de assistente social e sua intervenção junto às famílias}

Como antevisto, em seus primórdios, o Serviço Social não se constrói com identidade própria e visão crítica frente às desigualdades sociais que constituem expressões genuínas de seu objeto de trabalho. À época, nem mantém perspectiva transformadora nem tampouco emancipatória. Ao contrário. Sua ação, por muito tempo, repousa na ilusão de servir, como Martinelli (2011) chama atenção. Isto significou uma atuação guiada pela doutrina da Igreja Católica e executada por agentes sociais, que enfocam moralidade, submissão das classes dominadas, controle social da família operária e práticas assistencialistas, visando atender aos interesses da burguesia e à continuidade da ordem social vigente, como Freire e Cândido (2013) afirmam.

No Brasil, o Serviço Social emerge, em 1930, articulado com os processos econômicos, políticos e históricos do país, com o intuito de mediar as contradições existentes entre capital e trabalho. Os primeiros passos formativos das escolas de ensino superior da área têm em suas diretrizes o fundamento de adaptação dos indivíduos à vida social. O Serviço Social funda-se, pois, em vertente assistencialista-caritativa, ao tempo em que a questão social se amplia diante do avanço da urbanização e da industrialização brasileira.

Inevitavelmente, surgem políticas públicas de resposta às novas questões, o que exige melhor preparo profissional. Isto conduz os assistentes sociais a adotarem, anos 50, a vertente funcionalista norte-americana com o intuito de ampliarem a tecnificação e o preparo científico da área para o enfrentamento das mazelas sociais, ainda que não consigam romper com a individualização e a responsabilização dos indivíduos frente aos problemas emergentes. Somente anos depois, fundamentado na tradição marxista, fortalece-se o entendimento dos males como consequência da carência do mínimo necessário à sobrevivência dos cidadãos, diante das desigualdades produzidas pelo capitalismo.

Como Mioto (2010) ressalta, a família constitui sujeito privilegiado do trabalho profissional do Serviço Social desde sua origem. A priori, uma concepção de família orientada pelo conservadorismo católico; a posteriori, pelo funcionalismo que a prática profissional adota. Na mesma linha de pensamento, para Iamamoto (2000); Martinelli (2011); e Netto (1999), historicamente, o trabalho profissional obedece a certo controle, com enfoque psicologizante e moralizador centrado no indivíduo e na família, ou seja, o profissional atua normativamente na vida do trabalhador e de sua família. Os problemas sociais são percebidos como decorrentes da crise

Argum., Vitória, v. 10, n. 1, p. 276-292, jan./abr. 2018. 
de formação moral, intelectual e social da família. Com aporte teórico positivista/funcionalista da fase da consolidação da profissão, sobretudo, pós anos 40 e 50, aprofundase o conservadorismo no trato dos problemas do núcleo familiar.

Conforme Mioto (2010), o aporte teórico-metodológico então em voga traz como consequências: i) compreensão das relações sociais em plano imediato e a solução dos problemas sociais como encargo dos indivíduos e respectivas famílias; ii) acesso aos auxílios e serviços vinculados a transformações no modus vivendi das famílias; iii) estudos sociais direcionados a julgamentos morais com adoção de instrumentos e técnicas voltados ao processo de investigação e ao controle dos modos de vida; iv) visão da intervenção social como temporária, quando esgotadas possibilidades e recursos da própria família.

Com o amadurecimento da área e de seu profissional, especialmente, a partir da década de 6o, efetiva-se debate crítico frente à realidade para questionar as ações até então realizadas via análise de seus fundamentos teórico-metodológicos, ético-políticos e práticos:

[...] os profissionais passam a analisar criticamente suas intervenções, pois [com] a aproximação com os movimentos sociais na luta por seus direitos, criou-se a possibilidade de reflexão crítica de sua atuação despertando a busca de um referencial teórico que construísse uma ideologia de transformação social [...] (FREIRE; CÂNDIDO, 2013, p. 355).

As discussões teóricas não só fortalecem a visão crítica dos profissionais, mas também contribuem com a desmistificação da ilusão de servir, identidade atribuída ao Serviço Social pela burguesia. E é na década supracitada, que se inicia a busca pela identidade do Serviço Social no contexto latino-americano. Devido à instalação, no Brasil, da Ditadura Militar (1964-1985), esse movimento ganha força e adesão massiva nos anos 80 . Indo além, hoje, a profissão de assistente social é regulamentada pela Lei n. 8.662, de 1993 e mantém como guia para sua atuação o Código de Ética do assistente social, do mesmo ano, baseado em princípios de equidade e liberdade, de modo que tais elementos normativos assegurem relativa autonomia ao profissional no contexto das instituições empregadoras (BARROCO, 2009; FREIRE; CÂNDIDO, 2013).

Com a reconceituação da profissão de assistente social, concebida por Yazbek (2009) como renovação para fortalecimento de um novo projeto de atuação comprometido com as legítimas demandas das classes subalternas, os profissionais tendem a iniciar interlocução com as leituras marxistas. A iniciativa favorece avanço teórico-metodológico da área balizado pelo refinamento de referências técnicas, teóricas, éticas e políticas para o exercício profissional (NETTO, 1999) e, posteriormente, anos 90, pela elaboração do PEP, demarcado por valores humanos, princípios, objetivos e estratégias rumo a uma sociedade mais democrática em todas as instâncias, e, em sua essência, equânime, justa e igualitária.

A este respeito, Martinelli (2011) esclarece que o PEP não é unívoco. Pode até ser hegemônico, mas não é necessariamente único. Afinal, o coletivo profissional é, sempre, permeado por um campo de disputa de significados e diversidades, sendo, portanto, cabível e esperado o surgimento de projetos de diferentes naturezas. Independentemente desta ressalva, assegura-se, conforme Paiva e Sales (2003) alertam, que a categoria dos assistentes sociais, majoritaria- 
mente, sela compromisso ético-político, referenciando-se em ideais igualitários e libertários integrados às lutas sociais dos trabalhadores, bem como, em valores éticos que assegurem desenvolvimento pleno dos indivíduos.

Neste momento, questiona-se: o trabalho profissional, especialmente, com famílias de origem de crianças e/ou adolescentes em serviços de acolhimento institucional, vem conseguindo superar o conservadorismo, a individualização e a culpabilização das famílias?

Na verdade, quando da renovação da profissão, num primeiro momento, a discussão sobre família e o TSF ocupa segundo plano por uma série de fatores. Destaque para: i) exigências teórico-metodológicas impostas para a consolidação do Serviço Social no âmbito da teoria social crítica; ii) conservadorismo dessas temáticas em fase anterior e posterior à reconceituação; iii) ideia de que a temática seria de menor amplitude em termos de transformação das relações sociais. Este último fator, de acordo com Campos (2008) e Mioto (2010), pode advir da ausência ou carência de pesquisas, mantendo os assistentes sociais aprisionados a formas tradicionais de intervenção, impondo, então, pouca visibilidade às particularidades das ações profissionais.

Ainda quanto aos aspectos históricos da profissão dos assistentes sociais e sua intervenção junto às famílias, no decênio 9o, o tema TSF ressurge, no contexto das políticas sociais e da reforma do Estado brasileiro. Induzido pela ideologia neoliberal, passa a se estruturar na esfera do pluralismo de bem-estar social, enfatizando a responsabilização familiar. Problematizase a naturalização da função protetiva das famílias como socialmente construída tal como se dá com os modelos de organização familiar. Isto é, as famílias são enaltecidas como agentes naturais de proteção, e, por conseguinte, como corresponsáveis pela justiça social, o que corresponde ao incentivo para utilizar seus recursos e suas potencialidades visando reduzir as funções do Estado.

Vê-se que, embora o Serviço Social, majoritariamente, mantenha bases referenciais críticas que rompem, pelo menos em parte, com a visão da questão social individualizada e individualizante, ainda convive como modos de ser e agir do assistente social, que avigorem certo conservadorismo no trato das expressões da questão social e no TSF.

Porém, num segundo momento, a discussão parte para produzir conhecimentos sobre a família e o TSF com base em referências críticas e em consonância com o PEP. Nesta perspectiva, ganham menção os estudos pioneiros de Mioto (2004). Em sua visão, na política social e no trabalho profissional, detectam-se dois projetos referentes à relação família e proteção social: familista e protetivo. O primeiro vislumbra a família como fonte natural de proteção, capaz de restaurar uma sociedade solidária e integradora diante de políticas de caráter compensatório e temporário. Os eventuais fracassos do núcleo familiar são considerados como resultado da incapacidade de gerir e otimizar recursos; de desenvolver adequadas estratégias de sobrevivência e convivência; de mudar comportamento e estilo de vida; sendo, inclusive, chamado a (re)incorporar riscos sociais.

No segundo projeto - o protetivo - a proteção da família está diretamente relacionada à proteção que recebe para seus entes como indivíduos (direitos sociais individuais), ou para si mesmos, na condição de grupo, acessando benefícios e serviços de qualidade e cobertura uni- 
versal. Registra-se responsabilidade e efetiva garantia de direitos sociais a cargo do Estado, com redução da responsabilidade familiar. Neste caso, o projeto guia-se por referencial teórico crítico, cujo entendimento permite a captação de que os processos familiares derivam do entrecruzamento de múltiplas relações e fatores sociais, de tal forma que o TSF não pode ser compreendido apenas em meio às relações de afeto e de cuidado, ou melhor, não apenas nos intramuros da família.

Em síntese, o TSF no Serviço Social norteia-se por dois eixos. No primeiro, denominado por Mioto (2004), de normatividade e estabilidade, a família é vista como problema e o tipo de atendimento proposto atrela-se aos objetivos institucionais e não às demandas das famílias, como no projeto familista. O segundo eixo, denominado de conflito e transformação, volta-se para ações profissionais dirigidas às famílias, como sujeitos de direitos, visando à construção da cidadania e à materialidade dos direitos e da prática cidadã, presentes no projeto protetivo.

Em relação à utilização do paradigma marxista no Serviço Social e suas repercussões no Trabalho Social com Famílias, na linha de pensamento de Mioto (2010), tal modelo opera duas mudanças fundamentais para se repensar o trabalho com famílias. São elas: i) nova possibilidade de interpretação da demanda, não mais vista como casos de famílias ou incompetência dos sujeitos, mas analisadas como expressões de demandas humanas não atendidas e decorrentes da estrutura desigual da sociedade capitalista; ii) nova direcionalidade da ação profissional, em que a categoria dos direitos e da cidadania passa a mediar o encaminhamento das atividades, inserindo em seu modus operandi medidas que tratem a família como sujeito de direitos.

Para tanto, a autora referida assevera que o TSF precisa ser realizado a partir do pressuposto de que a família se constrói e se reconstrói, historicamente e cotidianamente, a partir de negociações entre seus membros e outras esferas da sociedade, como mercado e Estado. A família não pode ser concebida encastelada em determinada estrutura, considerada ideal e com papéis predefinidos, desconsiderando as transformações sociais em seu entorno. Sob esta ótica, o trabalho profissional guiado pela teoria marxista articula melhor as dimensões teóricometodológica, ético-política e técnico-operativa no trabalho cotidiano, assegurando intervenção na realidade mais qualificada, e, portanto, maior racionalidade crítico-dialética:

[...] penso ser necessário ao profissional acionar uma racionalidade que permita desenvolver uma instrumentalidade inspirada na razão dialética, que seja capaz de construir novas competências e legitimidades, que permita ao profissional dar novas respostas qualificadas em oposição às tradicionais respostas instrumentais, de maneira comprometida com valores de uma sociedade emancipada (GUERRA, 2000, p. 66).

Em relação ao trabalho com famílias nos serviços de acolhimento para crianças e adolescentes, o mesmo sofre alterações em função de: i) mudanças internas da profissão; ii) reordenamentos a partir de novas leis, como Estatuto da Criança e do Adolescente (ECA) (BRASIL, 1990); Plano Nacional de Promoção, Proteção e Defesa do Direito de Crianças e Adolescentes à Convivência Familiar e Comunitária (PNCFC); Política Nacional de Assistência Social (PNAS); e Norma Operacional Básica/Sistema Único de Assistência Social (NOB/SUAS). Aliás, os avanços na legislação e nas políticas sociais, ao tempo que geram novas demandas por TSF soam como contraditórias, pois ocorrem em meio a disputas entre projeto democratizan- 
te e projeto neoliberal. Ademais, há resistências por parte da cultura do abrigamento no Brasil em se alterar práticas sociais arraigadas na propalada ilusão de servir.

Quer dizer, apesar dos avanços normativos e operacionais, a rede de atendimento não atua de forma transversal e intersetorialmente, prejudicando a efetivação da proteção à criança e ao adolescente. Corroborando afirmação de Heleno e Ribeiro (2010, p. 19), acredita-se: “[...] um longo caminho para a operacionalização do que preconiza o ECA ainda precisa ser percorrido, pois muitas das mudanças ocorreram no plano legal e não no real.” Reconhece-se, porém, que grandes passos, ao longo das últimas décadas, têm favorecido crianças e adolescentes. Por exemplo, em 1948, a Organização das Nações Unidas aprova a Declaração Universal dos Direitos Humanos, cujo ideal é atingir todas as nações, o que representa efetivo avanço, haja vista que preconiza o valor primordial do ser humano e de seus direitos universais.

Em se tratando do Brasil, face à prevalência do caráter familista da política social, com intervenção espontânea ou incentivada da sociedade civil organizada (filantropia e Igreja) e da família, protegendo seus membros, na atualidade, apesar de a Constituição Federal de 1988 está fundada em princípios de justiça social e equidade, há muito a ser feito. $\mathrm{O}$ avanço das reformas neoliberais desmantela e ressignifica as prescrições constitucionais numa lógica liberal e de desregulamentação do papel de proteção social do Estado, reforçando as atribuições dessas funções na família.

\section{Centralidade da família na Política de Assistência Social e orientações metodológicas para o trabalho nas instituições de acolhimento}

A PNAS adota a matricialidade sociofamiliar como eixo estruturante da política. Influenciada por organismos internacionais, expressa o reordenamento das políticas sociais, segundo o qual não se pode fazer política pública sem parcerias e a família persiste como instância insubstituível na proteção social. É agente e parceira em cuidados, atenção, assistência e cumprimento de deveres e contrapartidas de benefícios e serviços. Reforçam-se, portanto, as funções clássicas da família, como a de socialização, educação, cuidados, guarda, sobrevivência. Logo, família como uma unidade de serviços e uma unidade econômica (gerir a sobrevivência), incompatíveis com os novos formatos de família e os acúmulos de vulnerabilidades sociais.

Neste contexto, assume-se, cada vez mais, que o dever de proteção é da família e delega-se a ela a maior parte da responsabilidade. Eis uma posição típica do familismo, como enunciado. Na acepção de Goldani (2005), há muita expectativa em relação à família na proteção social e a política social, implicitamente ou explicitamente, é pensada tomando a família como referência. Como decorrência, a noção de direitos, a questão do dever do Estado, a política pública que garanta cidadania e que atue sobre a reprodução social de modo a minimizar as funções da família (projeto protetivo) vão se perdendo. O processo de responsabilização ampara-se em diferentes dispositivos legais que afiancem a delegação de responsabilidades, ou seja, a legislação vigente obriga a solidariedade familiar (MIOTO; CAMPOS; LIMA, 2006; TEIXEIRA, 2013).

E mais, a PNAS hierarquiza as proteções sociais oferecidas pela política em duas instâncias: básica e especial. Na básica, estão os serviços de prevenção das situações de risco e de enfretamento das vulnerabilidades sociais. Na especial, estão os serviços para os casos de violação

Argum., Vitória, v. 10, n. 1, p. 276-292, jan./abr. 2018. 
de direitos. Neste, destacam-se os serviços de acolhimento institucional, que constituem medida de proteção para crianças e adolescentes, cujos direitos foram violados, lhes afastando temporariamente das famílias de origem. No entanto, com reformulações do ECA e do PNCFC, a Tipificação Nacional dos Serviços Socioassistenciais e Orientações Técnicas para os serviços de acolhimento, registra-se nova demanda para o trabalho social nesses serviços com recomendações metodológicas previamente prescritas.

A publicação Orientações técnicas: serviços de acolhimento para crianças e adolescentes (CONSELHO NACIONAL DE ASSISTÊNCIA SOCIAL, 2009) inclui orientações metodológicas e elementos variados. Dentre eles: i) diagnóstico que arrole os motivos do afastamento da criança ou do adolescente das famílias; ii) Plano Individual e Familiar de Acompanhamento (PIA), que delineie estratégias de trabalho junto ao segmento institucionalizado e à família de origem visando à reintegração familiar; iii) acompanhamento da família de origem, mediante encaminhamentos e ações contínuas com as famílias durante a fase de acolhimento; iv) trabalhos em redes que incorporem articulação entre os setores, como participação em audiências concentradas, estudos de caso, encaminhamento às políticas sociais e respectivos serviços. Ao estudar tais orientações, Cronemberger (2017) identifica fins conflitantes que mais reforçam as responsabilidades familiares do que oferecem condições de superação das situações de vulnerabilidade e de risco social, como as dos ciclos de pobreza e de violação de direitos.

De fato, muitos profissionais que implementam políticas públicas, a exemplo dos assistentes sociais, podem, se lhes falta clareza dos objetivos e das finalidades de cada política, e, também, dos fins e da direção do PEP, reproduzir o fenômeno de individualização e culpabilização das famílias, que ainda persiste nas políticas sociais. Isto ocorre, quando aderem aos objetivos do TSF sem postura crítica.

Quando do processo de culpabilização, os profissionais de Serviço Social são chamados a opinar e a emitir pareceres, fundamentados na lógica das funções, incompetências e desestruturações familiares. Para Mioto (2003), esses assistentes sociais convocados para solucionar casos de violência a que crianças e adolescentes são submetidos, nem sempre percebem que põem em prática uma concepção prévia das causas do problema. Muitas vezes, individualizam a questão como casos de famílias e não como expressão da questão social:

\footnotetext{
Assim a família é cada vez mais colocada na berlinda. Ora como culpada, ora como vítima, ora como violenta, ora como protetora, a família vai se transformando cada vez mais em objeto de intervenção de um número cada vez maior de profissionais das mais diferentes áreas. Esses profissionais, chamados a apresentar soluções para as situações de violência, nem sempre se dão conta que suas ações colocam em movimento determinadas formas de análises sobre a relação família e violência, construídas a partir de diferentes concepções de sociedade e de família (MIOTO, 2003, p. 97).
}

As negligências ocupam o topo dos motivos da retirada das crianças do seio familiar. Entretanto, trata-se de conceito complexo que só deve ser aplicado em situação ou contexto de vida. Isto porque, quando subjetivo e fora da conjuntura vivenciada, termina por gerar a culpabilização da família. Aliás, as palavras de Baptista e Volic (2005) são pertinentes para entender o que parece contrassenso: 
As pessoas só são passíveis de ser responsabilizadas por negligência quando possuírem as condições para atender às necessidades daqueles que estão aos seus cuidados e voluntariamente se omitirem. Esses cuidados estão relacionados às necessidades básicas fundamentais, que podem ser materiais, psicológicas e sociais (BAPTISTA; VOLIC, 2005, p. 151).

Acredita-se que o TSF desenvolvido pelo assistente social pode desnaturalizar as funções atribuídas às famílias fora de sua existência material e subjetiva, ou melhor, fora da sociabilidade capitalista. Mesmo assim, há quem ainda não perceba as contradições das políticas sociais e se reja por elas como referencial teórico, adotando-as sem críticas consolidadas. Para o profissional de Serviço Social intervir junto às famílias precisa capacitar-se e se aliar às forças sociais com o fim de alterar a política e superar visões disciplinadoras ainda presentes no TSF.

\section{Trabalho Social com Famílias de Origem em Serviços de Acolhimento Institucional no Piauí}

Segue parte dos resultados da pesquisa de campo realizada junto a assistentes sociais em seu ambiente de trabalho, qual seja, instituições que oferecem acolhimento de forma integral a crianças e/ou adolescentes em situação de abandono ou vítimas de maus-tratos ou de violência, além de profissional vinculado à $\mathbf{1}^{\underline{a}}$ VIJ da capital piauiense. Inscritas no Conselho Municipal dos Direitos da Criança e Adolescentes de Teresina, eis as nove instituições: (I) gestão estadual: Lar Maria João de Deus; Abrigo Feminino; Abrigo Masculino; (II) gestão municipal de Teresina: Casa Reencontro; Casa de Punaré; (III) gestão municipal de Parnaíba: Casa de Acolhimento Infanto-Juvenil; (IV) organização não governamental: Casa Dom Barreto; Casa Savina Petrilli; Casa de Acolhimento Livre Ser.

Segundo a NOB/SUAS (BRASIL, 2011), a equipe de referência nos serviços deve integrar um coordenador de nível superior; um assistente social (para cada 20 usuários); um psicólogo (também para cada 20); um cuidador, cada 10. Como a pesquisa prioriza o Trabalho Social com Famílias de origem, sobretudo, pelo fato de o TSF ocupar lugar central nos discursos dos assistentes sociais, os depoentes são sempre assistentes sociais.

Assim, o trabalho social com a família de origem (ou TSFO) nas instituições de acolhimento investigadas, a partir das referências críticas da profissão, pode ser visto como ação significativa junto às famílias de origem ou em prol delas, na efetivação da garantia e da ampliação dos direitos de crianças e/ou adolescentes e de suas famílias, no enfrentamento das expressões da questão social. Por isso, exige-se a ampliação da ação profissional para além dos sujeitos singulares que serve de subsídio para as respostas coletivas às demandas que são aparentemente singulares, podendo ocorrer por meio de reuniões, entrevistas, visitas domiciliares e visitas institucionais, realização de dinâmicas de grupo, ações que oportunizam o TSF face a face com as famílias ou em outras formas, como na criação de serviços ou na articulação entre eles.

Nas instituições de acolhimento, quando da operacionalização do TSFO, segundo as orientações técnicas (CONSELHO NACIONAL DE ASSISTÊNCIA SOCIAL, 2009), devem se considerar tanto as questões objetivas quanto as subjetivas. Nas primeiras, está envolta a prevenção de situações que conciliem o cuidado com o acolhido e a sobrevivência do núcleo familiar. As situações subjetivas, por seu turno, devem ser analisadas, porque podem dificultar as relações afetivas contributivas para a prática de cuidados. De qualquer forma, o objetivo macro é sem-

Argum., Vitória, v. 10, n. 1, p. 276-292, jan./abr. 2018. 
pre apoiar a família no processo de reintegração do semento afastado e na prevenção de novos afastamentos.

As questões de vínculos e cuidados ganham centralidade no trabalho previsto, o que expressa às contradições de como a família é incluída na PNAS. Embora, essas questões sejam importantes, é fundamental o enfrentamento de vulnerabilidades e fragilidades das condições de vida, para só então investir em questões culturais e subjetivas. Sem esse aporte da rede de serviços, o trabalho torna-se mero aconselhamento fundado em mudanças comportamentais, sem atingir as causas determinantes dos problemas.

Uma das atribuições profissionais nos serviços de acolhimento é a elaboração do citado PIA. Parte do diagnóstico sobre os motivos do acolhimento e sobre a realidade das famílias de origem para elaborar estratégias e traçar ações para o enfrentamento dos motivos identificados, com o intuito de reintegração familiar dos acolhidos. Assim sendo, o PIA deve prever ações sistemáticas junto às crianças e/ou aos adolescentes e às suas famílias, o que pressupõe participação efetiva dos familiares.

Como expressa alguns depoimentos coletados, o Plano é um procedimento complexo e passo inicial para ação nas instituições de acolhimento. Pode-se argumentar que ele tecnifica as intervenções, mas o PIA não é um procedimento neutro. Ao contrário. De acordo com a perspectiva teórico-metodológica e ideo-política, pode dirigir as ações, seja para manter o status quo, que interpreta os problemas como de responsabilidade familiar, ou para alterá-lo e inserir as famílias na rede de políticas sociais com direito à proteção social. Eis uma das falas representativas dessa percepção:

\footnotetext{
Nós temos o PIA, nosso maior instrumento. Tudo cai nele! É [...] muito trabalho para realizar, porque ele é muito completo. Ele tem informações, bem assim, 'primícias' mesmo até o momento atual. E já é, assim, traçada a história da criança e do adolescente. Mas nós trabalhamos também com fichas de visitas domiciliares. Todas as visitas que fazemos, são documentadas. A pessoa que recebe a visita, assina um documento de que recebeu a visita. Nós temos relatórios. Esses relatórios, dividimos assim: temos o relatório psicossocial [...] E a maioria das intervenções é realizada conjuntamente. Então, fazemos o [relatório] psicossocial. Mas no psicossocial, nós temos pontos específicos do assistente social e, também, do psicólogo. O olhar dele e o meu. Depois, emitimos parecer diante da situação. O Plano, o relatório, a estrutura do relatório, a gente percebe que atende às necessidades [...] Ela [a família] descreve a situação da escola, a relação com a comunidade, a relação com os acolhidos, com os cuidadores, com os profissionais, com a família e depois a gente faz uma avaliação global de como está essa família hoje ou de como ela se apresenta. Depois damos o parecer [...] Se há necessidade de permanência da criança ou do adolescente na casa, ou então, de sua reintegração. Geralmente, nós fechamos o PIA para levar para audiência para a gente definir mais ou menos como é que vai ficar a situação (Assistente Social J.).
}

Uma das vias mais apontadas para enfrentar as situações de vulnerabilidades e de risco social das famílias tem sido o trabalho em rede: rede de defesa de direitos; rede de atendimento; rede intersetorial. Para tanto, a escuta individual das famílias por meio de entrevistas, faz parte do TSFO, bem como os encaminhamentos para a rede, conforme as demandas das famílias, como relata o assistente social $\mathrm{H}$.: 
A gente faz o trabalho com as famílias de origem, quando a criança vai acolhida. A gente sempre procura algum número de contato ou endereço, se o CRAS [Centro de Referência de Assistência Social] e o CREAS [Centro de Referência Especializado de Assistência Social] já fazem o acompanhamento [...] A gente busca entrar em contato com CRAS, CREAS, Conselho, também, para fazer uma visita inicial da família. Na visita, a gente [...] tem contato com a família. A gente já aciona também a Vara da Infância [e Juventude] para saber se a família tem autorização para visitar a criança na casa de acolhimento ou também de manter contatos telefônicos. Quando tem permissão, a família visita os filhos uma vez na semana, aos sábados, quando acontecem também os atendimentos individuais (Assistente Social H.).

Na fala transcrita, evidencia-se a incipiência do TSFO, principalmente, quanto à limitação de seu desenrolar, como acompanhamento e trabalho socioeducativo com os grupos de famílias. Este se dá aos sábados - dia de visita -, comprometendo tanto as horas de interação entre família e abrigado quanto o atendimento individual. Se é mais cômodo para o profissional atender individualmente a família nos dias de visita, relegam-se duas grandes categorias do processo: o trabalho com a família e o estímulo à convivência familiar.

Nesta perspectiva, uma intervenção com base no PEP e nos referenciais críticos encontram limitações estruturais. Dentre elas, como Mioto (2016); Guerra (2000); e Teixeira (2016) analisam, destacam-se as condições de vida e materiais das famílias, que lhes dificultam ir às instituições, aliadas às expectativas sociais sobre a própria família fomentadas pela política pública e aliadas ao pragmatismo e imediatismo das intervenções profissionais.

O trabalho propriamente dito com a família de origem começa pela escuta qualificada, por meio de entrevista ou visita domiciliar. Durante a entrevista (diálogo com objetivos planejados antecipadamente, em comunicação direta), compete ao assistente social conduzir a conversa, direcionando-a para os fins pretendidos, seja o de levantar/prestar informações, estabelecer contatos, fazer encaminhamentos, etc.

A este respeito, Cruz Neto (2004) reforça que, se a defesa da democracia e o respeito à diversidade são valores fundamentais da atuação do assistente social, o momento da entrevista consiste em espaço onde o usuário manifesta ideias, vontades e necessidades, ou seja, pode ser escutado. Decerto, estabelecer tal relação é fundamental. Se as famílias não tiverem tal direito básico respeitado, o processo de intervenção em sua totalidade será prejudicado. De forma similar, as visitas domiciliares constituem fonte de levantamento de informações, essenciais ao acompanhamento das famílias, sempre a partir das referências críticas e em consonância com os valores defendidos no PEP.

No trabalho social nas instituições de acolhimento, uma das dimensões metodológicas previstas é o trabalho em rede. Consiste em encaminhamento para outros serviços como estratégia do TSFO no enfrentamento das vulnerabilidades sociais. Não se trata de transferência de responsabilidade para setores diversificados, mas, sim, o acompanhamento sistemático do atendimento em outros serviços e dos resultados daí advindos. Isto é, as gestões devem adotar protocolo de ações integradas, fluxo de rotinas, definição de encargos entre serviços e instituições para garantir a contrarreferência, ou seja, o retorno consubstanciado das conduções. Sem essa via de mão dupla - referência e contrarreferência - o trabalho fica sem efetividade e sem alicerce para emissão de pareceres ou para avaliação do trabalho desenvolvido.

Argum., Vitória, v. 10, n. 1, p. 276-292, jan./abr. 2018. 
Também o acompanhamento da família deve ser sistemático para que, num prazo de até dois anos (respeitando-se os princípios da provisoriedade e excepcionalidade), viabilize-se o retorno do abrigado ao convívio familiar. Quando impossível, envio para família extensa. Em último caso, adoção. Quer dizer, o tempo de permanência nos serviços de acolhimento institucional para crianças e adolescentes figura como um dos eixos principais de avaliação acerca das medidas a serem tomadas.

[...] Nós estamos tratando de vida, desenvolvimento cognitivo, desenvolvimento pessoal. Quanto maior delongada a decisão, pior para a criança, para o adolescente. Quer dizer, quanto mais célere for o retorno, mais célere é o resultado [...] Às vezes, a demanda é favorável, mas, na maioria, é desfavorável [...] Se você manda um [...] relatório perfeito, com todas as alternativas, para quê esperar? Por que a demora de mais um pedido de providência, de mais demora para uma audiência? A audiência é de seis em seis meses. Hoje, já acontece antes (Assistente Social J.).

Em suma, é preciso avaliar os prejuízos ao desenvolvimento do acolhido que possam advir tanto da permanência prolongada quanto do rompimento definitivo dos vínculos com a família de origem.

O acolhimento tem que ser uma medida realmente excepcional. Tem que ser a última medida. Tirar a criança ou adolescente do lar [...] é bem complicado. A gente observa que as crianças que estão há mais tempo acolhidas, com o passar do tempo, [...] querem liberdade. Quando você tem uma criança ou adolescente em casa, normalmente, se vai ao supermercado, à farmácia. Sai para qualquer lugar. Aquilo dali é novo. E a casa de acolhimento, não. Fica muito tempo na instituição. Fica muito tempo acolhida. Claro, há atividades que a gente desenvolve, mas não suprem as da família (Assistente Social B.).

Embora o tempo seja um eixo central, as decisões não podem ser prematuras ou precipitadas. Quando a reintegração familiar ocorre sem preparação adequada do núcleo familiar e da criança e/ou adolescente, pode se tornar conflituosa e resultar em novo afastamento. O ideal é afiançar o Direito à Convivência Familiar e Comunitária (DCFC) sem prolongar em demasia o tempo do acolhimento:

[...] realizar um trabalho psicossocial levando sempre em consideração o caráter excepcional e provisório do acolhimento. Deve assumir como necessidade fundamental e prioritária a preparação da reintegração familiar de forma protegida. Para isso, torna-se imprescindível o acompanhamento à família de origem/extensa em corresponsabilidade com a rede de proteção e Vara da Infância e da Juventude para que, com qualidade, as ações possam ocorrer de maneira ágil, como o próprio momento da criança e adolescente exige [...] (VALENTE, 2012, p. 582).

Além do trabalho em rede de várias políticas públicas, a ação socioeducativa deve ser parte desse trabalho, especialmente, o trabalho em grupo que favorece discussões coletivas e ampliação do olhar sobre o problema. De acordo com Godinho (2012, p. 21), a

[...] abordagem metodológica pauta-se num processo de reflexão em que a família possa ampliar sua percepção sobre a dimensão dos aspectos individuais e coletivos da situação vivenciada, observando as interferências culturais, econômicas, sociais, objetivas e subjetivas, para a partir disso decidir, optar, desenhar as alternativas e decidir 
sobre a própria história com as informações da rede disponíveis e com sua capacidade de escolha (GODINHO, 2012, p. 21).

Entretanto, os depoimentos coletados na pesquisa nem sinalizam uma sistemática grupal para o trabalho nem ressaltam como e o que é discutido com as famílias nas visitas domiciliares e nas entrevistas nos dias de visita. Em geral, registra-se o que Cronemberger (2017) analisa sobre as orientações metodológicas para os serviços. Isto é, processos individualizadores e culpabilizadores, reproduzidos no trabalho profissional cotidiano, fundado no aconselhamento e na busca de compromissos familiares, movidos pela vontade de não mais violar direitos, sem qualquer alteração nas condições objetivas e subjetivas de vida. Como decorrência, os novos valores do PEP, da renovação da profissão e das novas direções e acúmulos teóricos sobre o TSF ainda mantêm dificuldades de se materializarem em estratégias e ações.

Ora, o trabalho em rede sem contrarreferência ou ação socioeducativa sem trabalho em grupo dificulta a reintegração familiar e a participação qualificada nas audiências, além de relatórios e pareceres favoráveis às famílias. Afinal, não há registro de melhoria de suas condições de vida nem tampouco compreensão da problemática vivenciada. Como então superar culturas de violação reproduzidas entre gerações e no interior das famílias? Assim, ainda são inúmeros os desafios do trabalho do assistente social, dentre os quais está o trabalho em rede. No entanto, este pode ser visto como possibilidade de um fazer diferenciado do tradicional. Em vez de circunscrito a um setor específico, assume perspectiva interdisciplinar e intersetorial capaz de atender às demandas das famílias.

Porém, ao longo do estudo, ainda que alguns entrevistados apontem percurso conveniente para a identificação dessas demandas, são perceptíveis os desafios por eles enfrentados, devido à fragilidade da rede de serviços. Por exemplo, quando se precisa de algo, às vezes, não há serviço adequado ou a demora dificulta todo o trabalho em andamento nas instituições de acolhimento. Noutras ocasiões, os profissionais recorrem às suas redes informais de apoio, imediatizando a intervenção para minimizar uma questão momentânea e que, sem acompanhamento da informalidade, não teria solução.

[...] só para ilustrar: solicitei uma cesta básica para o CRAS há dois meses. Nem a visita, o CRAS não fez ainda! E detalhe: a cesta é para uma pessoa que precisa muito: o filho está aqui [...], a filha está aqui [...], o outro filho está sozinho na casa e a mãe está em tratamento, porque usa droga. O menino come em casa de vizinhos. Nós já fizemos muitas cestas básicas e entregamos para eles [...] Procuramos nossas amigas para ajudar [...] porque na casa não tem nada [...] (Assistente Social B.).

A articulação de serviços de forma célere, acesso a benefícios monetários e eventuais ou outras formas de benefícios ainda são importantes na superação da pobreza e suas repercussões nas relações interpessoais e familiares. São desafios que se ampliam na conjuntura de corte nos gastos públicos e no congelamento do orçamento das políticas sociais. Vê-se quão perceptível é o desafio para assegurar uma reintegração familiar segura, por inexistirem subsídios para a família, a exemplo de uma rede integral de serviços públicos, a qual afiance seus direitos, incluindo a complementação de renda. Sem ela, o que se vê é a penalização da família.

Aliado a tudo isto, ainda se percebe ineficácia do trabalho socioeducativo junto às famílias, o denominado acompanhamento familiar. Nem sempre por conta da falta de competência e cri-

Argum., Vitória, v. 10, n. 1, p. 276-292, jan./abr. 2018. 
atividade dos profissionais. Em grande parte, face às condições adversas de atuação, como registra um dos pesquisados:

\begin{abstract}
Não temos trabalho em grupo. Só, atendimentos. A gente buscou fazer por duas vezes um grupo com as famílias presentes. Porém, devido à demanda e ao tempo curto (as visitas duram de o8:0o às 11:ooh), a gente preferiu fazer atendimento individual. Porque alguns são da mesma região e acabam mantendo vínculos ou tendo contato fora. Só que a gente não conseguiu estabelecer um grupo. A gente faz os atendimentos individuais a cada familiar que está ali (Assistente Social H.).
\end{abstract}

Em outras palavras, o assistente social não consegue superar o individualismo, muitas vezes, presente na pauta dos motivos de acolhimento. O atendimento é, com frequência, emergencial e circunstancial, o que não favorece ação sistemática e planejada em curto, médio e longo prazo. Não se vai além do aconselhamento ou do compromisso da família em não mais violar tão somente por questões morais. Isto termina por naturalizar e reproduzir práticas normativas criadas socialmente e culturalmente em torno dos papéis sociais familiares.

\title{
5 Considerações Finais
}

A partir dos resultados discutidos, infere-se que o TSF, na maioria das vezes, é imediatista e sem encadeamento de ações que assegurem suporte à emancipação e à reintegração familiar. Esta, por sua complexidade, acaba pouco privilegiada, diante das dificuldades enfrentadas, obstruindo-se o verdadeiro sentido do Direito à Convivência Familiar e Comunitária, embora seja ele condição sine qua non para proteção, crescimento e desenvolvimento de crianças e adolescentes.

No entanto, a bem da verdade, os dados apontam que a garantia do DCFC, em sua condição de direito social, não depende da família e de suas estratégias de sobrevivência. Deriva de condições objetivas asseguradas, teoricamente, pelo poder público, a exemplo de serviços de apoio, cuidados, socialização, acesso à renda e ao trabalho, e enfrentamento às drogas, tudo isto como sustentáculo do trabalho social com a família de origem. O TSFO inclui o trabalho socioeducativo que visa refletir e gerar ações que rompam com a cultura de violação, desrespeito e negligência, a partir da compreensão de seus determinantes, de sua reprodução dentre as famílias e fora delas, entre diferentes gerações da mesma família, sua associação a ciclos de pobreza, ao uso de álcool e drogas, e a transtornos mentais, que devem ser revistos para mudar percepção, compreensão e práticas violadoras.

Sob esta ótica, entre os grandes desafios enfrentados pelo TSFO, está a necessária releitura dos problemas que a família traz para além da individualização, o que pressupõe debates sobre o cotidiano familiar, sua problematização e desnaturalização, visando à busca de solução para tais problemas no âmbito das políticas públicas, rompendo com a lógica de soluções restritas aos intramuros da família.

No caso específico do Piauí, nos serviços de acolhimento institucional implementado, como visto, tanto por organizações governamentais quanto não governamentais, o TSFO é ainda episódico, pontual e assistemático. Inexiste prioridade para ele, talvez, por resistência da cultural institucional, responsável pelo acolhimento de crianças e/ou adolescentes, sem preocu- 
pação efetiva com as respectivas famílias. Ou seja, a pesquisa atesta que o trabalho com a família prossegue restrito às entrevistas nos dias de visita, ligações telefônicas para identificá-la e eventuais visitas domiciliares. Porém, com o reordenamento, a partir dos atuais dispositivos legais que colocam o DCFC como eixo central e para materializá-lo, o TSFO assume o objetivo de atender à família e prepará-la para a reintegração familiar.

Há que se resgatar a política social pública, sua confiabilidade e coerência, elementos que devem se assentar em conhecimento criterioso da realidade e no comprometimento da gestão pública com as legítimas demandas das famílias. Nesse cenário, o assistente social deve atuar com competência teórico-metodológica, politica-ética e técnica-operativa, politica, desvelando, as questões apresentadas. Por isso, as famílias de origem só podem ter participação qualificada e interveniente nas políticas públicas, quando mantêm instrumentos adequados de análise da realidade: quanto mais eficaz sua participação, mais eficiente a reintegração familiar.

O trabalho em rede aparece como elemento inibidor, face à carência de serviços, equipes interprofissionais, contrarreferência, e ações integradas e articuladas. Entretanto, representa uma possibilidade antes não utilizada: lançar mão de uma rede intersetorial, capaz de mobilizar trabalhadores e estratégias de forma articulada e integrada com vistas ao planejamento e à avaliação de resultados. Por fim, acredita-se que todas estas medidas, no caso do PI, asseguram que o Serviço Social como área de conhecimento e o assistente social, como profissional, podem superar, gradativamente, o conservadorismo, a individualização e a culpabilização, em se tratando das famílias de origem de crianças e/ou adolescentes em serviços de acolhimento institucional.

\section{Referências}

BAPTISTA, M. V.; VOLIC, C. Aproximações ao conceito de negligência. Serviço Social \& Sociedade, São Paulo, ano 26, n. 83, p. 147-156, set. 2005.

BARROCO, M. L. S. Fundamentos éticos do Serviço Social. In: BARROCO, M. L. S. Serviço Social: direitos sociais e competências profissionais. Brasília (DF): CFESS; ABEPSS, 2009. p. 165-184.

BRASIL. Presidência da República. Lei n. 8.o69, de 13 de julho de 199o. Dispõe sobre o Estatuto da Criança e do Adolescente [ECA] e dá outras providências. Brasília (DF), 1990. Disponível em: <http://www.planalto.gov.br/Ccivil_o3/leis/L8069.htm>. Acesso em: 14 nov. 2017.

BRASIL. Secretaria Nacional de Assistência Social. NOB-RH Anotada e Comentada. Brasília (DF), 2011. Disponível em:

<http://www.mds.gov.br/webarquivos/publicacao/assistencia_social/Normativas/NOB-

RH_SUAS_Anotada_Comentada.pdf>.Acesso em: 6 mar. 2018.

CONSELHO NACIONAL DE ASSISTÊNCIA SOCIAL. Orientações técnicas: serviços de acolhimento para crianças e adolescentes. Brasília (DF), 2009. 
CAMPOS, M. S. As metodologias e seus componentes: conferência, metodologia do trabalho social. São Paulo: PUCSP, 2008.

CRONEMBERGER, I. H. G. M. O processo de trabalho da/o assistente social nos serviços de acolhimento institucional no Estado do Piauí. 2017. 316 f. Tese (Doutorado em Políticas Públicas)-Universidade Federal do Piauí, Teresina, 2017.

CRUZ NETO, O. O trabalho de campo como descoberta e criação. In: MINAYO, M. C. de S. (Org.). Pesquisa social: teoria, método e criatividade. 23. ed. Petrópolis: Vozes, 2004.

FREIRE, A. dos S.; CÂNDIDO, S. da S. Uma análise da origem do Serviço Social no Brasil. Lagarto (SE): Revista Eletrônica da Faculdade José Augusto Vieira, 2013. Disponível em: <http://fjav.com.br/revista/Downloads/edicaoo8/Artigo_348_364.pdf>. Acesso em: 5 dez. 2017.

GODINHO, I. C. Uma reflexão sobre o trabalho com famílias na Política de Assistência Social. Sociedade em Debate, Pelotas, v. 18, n. 1, p. 9-30, jan./jun. 2012.

GOLDANI, A. M. Reinventar políticas para familias reinventadas: entre la "realidad" brasileña y la utopía. In: REUNIÓN DE EXPERTOS POLÍTICAS HACIA LAS FAMILIAS, PROTECCIÓN E INCLUSIÓN SOCIALES, Los Angeles. Papers... Los Angeles: CEPAL, 2005.

GUERRA, Y. Instrumentalidade do processo de trabalho e Serviço Social. Serviço Social e Sociedade, São Paulo, ano 20, n. 62, p. 5-34, mar. 2000.

HELENO, C. T.; RIBEIRO, S. M. Criança e adolescente: sujeitos de direitos. Belo Horizonte: Conselho Regional de Psicologia de Minas Gerais, 2010.

IAMAMOTO, M. V. O Serviço Social na contemporaneidade: trabalho e formação profissional. 3. ed. São Paulo: Cortez, 2000.

MARCONI, M. de A.; LAKATOS, E. M. Técnicas de pesquisa. 7. ed. São Paulo: Atlas, 2011.

MARTINELLI, M. Serviço Social: identidade e alienação. 16. ed. São Paulo: Cortez, 2011.

MIOTO, R. C. Trabalho Social com Famílias: entre as amarras do passado e os dilemas do presente. In: TEIXEIRA, S. M. (Org.). Política de Assistência Social e temas correlatos. Campinas: Papel Social, 2016.

MIOTO, R. C. Família, trabalho com famílias e Serviço Social. Serviço Social em Revista, Londrina, v. 12, n. 2, p. 163-176, 2010.

MIOTO, R. C. Que família é essa. In: WANDERLEY, M. B.; OLIVEIRA, I. C. (Org.). Trabalho com famílias: textos de apoio. São Paulo: PUCSP, 2004. v. 2. 
MIOTO, R. C. Para que tudo não termine como um caso de família: aportes para o debate sobre a violência doméstica. Revista Katálysis, Florianópolis, v. 6, n. 1, p. 96-103, 2003.

MIOTO, R. C.; CAMPOS, M. S.; LIMA, T. C. S. Quem cobre as insuficiências das políticas públicas? Contribuição ao debate sobre o papel da família na provisão de bem-estar social. Revista de Políticas Públicas, São Luís, v. 10, n. 1, p. 165-183, jan./ jun. 2006.

NETTO, J. P. A construção do Projeto Ético-Político Profissional frente à crise contemporânea. Brasília (DF): UnB; CEAD, 1999.

PAIVA, B.; SALES, M. A nova ética profissional: práxis e princípios. In: BONETTI, D. A. (Org.). Serviço Social e ética: convite a uma nova práxis. São Paulo: Cortez, 2003.

TEIXEIRA, S. M. Política de Assistência Social e o Trabalho Social com Famílias: trajetória histórica e atualidade. Ribeirão Preto (SP): Anais do Encontro Nacional de Pesquisadores em Serviço Social, 2016.

TEIXEIRA, S. M. A família na Política de Assistência Social: concepções e as tendências do Trabalho Social com Famílias nos CRAS de Teresina - PI. Teresina: EDUFPI, 2013.

VALENTE, J. Acolhimento familiar: validando e atribuindo sentido às leis protetivas. Serviço Social, São Paulo, n. 111, p. 576-598, jul./set. 2012.

YAZBEK M. C. Classes subalternas e assistência social. 4. ed. São Paulo: Cortez, 2009 .

Izabel Herika Gomes Matias CRONEMBERGER. Trabalhou na concepção, delineamento, coleta, análise, interpretação dos dados e redação do artigo.

Assistente Social. Doutora em Políticas Públicas (UFPI); Mestre em Políticas Públicas (UFPI); Especialista em Administração de Recursos Humanos (UFPI); Docente do Centro Universitário Santo Agostinho (UNIFSA).

Solange Maria TEIXEIRA. Trabalhou na concepção, estruturação do artigo, análise dos dados e revisão crítica. Pós-Doutora em Serviço Social (PUCSP), Doutora em Políticas Públicas (UFMA). Docente do Departamento de Serviço Social e do Programa de Mestrado e Doutorado em Políticas Pública da Universidade Federal do Piauí (UFPI). 